\title{
Impact of medium of instruction during school education on the academic performance of medical students: An observational study
}

\author{
Deepmala Nagorao Deore ${ }^{1}$, Yogesh Balasaheb Gavali ${ }^{2, *}$ \\ ${ }^{\mathbf{1}, \mathbf{2}}$ Associate Professor, Dept. of Physiology, ${ }^{1}$ CSMSS Dental College, Aurangabad, Maharashtra, ${ }^{2}$ Sree Narayana \\ Institute of Medical Sciences, Chalakka, Ernakulam, Kerala, India
}

\section{*Corresponding Author}

Email: ybgavali@gmail.com

\begin{abstract}
Introduction: Many of the students admitted in Indian medical colleges have had school education in vernacular medium. There exists a general opinion that such students find it difficult to cope up with medical academics in English medium as they think in one language and study in another. This study was carried out to find whether such language barrier affects their professional performance.

Materials and Methods: This multi-centric retrospective observational study was carried out in 274 medical students from four government medical colleges in Marathwada region of Maharashtra, India. The medium of instruction during their school education was recorded from their $10^{\text {th }}$ standard mark-sheets. The marks of final year MBBS were obtained from their academic record in academic section of the colleges. The data were analysed using one-way ANOVA.

Result: There was statistically no significant difference of professional performance among the medical students with different media of instruction in their school education $(\mathrm{P}=0.1149)$.

Conclusion: Medium of instruction of school education doesn't have any significant effect on professional performance of medical students.
\end{abstract}

Keywords: Medium of instruction, Mother tongue, Language barrier, Professional performance.

Received: $26^{\text {th }}$ September, 2017

\section{Introduction}

There are nearly 5,000 languages in use in the world today. Every advanced country has its own national language. India has more languages compared to any other country in the world. Hindi is the primary language spoken by $30 \%$ of Indian population. Marathi and Urdu are the major languages of communication and instruction in Marathwada region of Maharashtra. English though not a primary language but is ubiquitous to India, a former British colony. English is certainly very important in higher education and played a crucial role in developing India as an economic power. ${ }^{1}$ English language as a medium of instruction plays the key role in medical students' learning in India. Therefore, it is the popular belief in the society that the students' academic achievement depends largely on their English language abilities.

But productive learning process does not rely only on the knowledge about English language, it also involves other factors like communication skills, supportive teachers, supportive home environment and motivation. Learners get actively involved in the learning process through discussion, reading, writing, and analysis, rather than passively getting instructions. To learn, students have to communicate and exchange the information among them, which needs fair understanding of language. Being a tool to communicate, language allows students to convey ideas, facts, concepts and feelings to each other, which may be better done through their mother tongue or vernacular medium of instruction.

Studies show that medical undergraduates undergo multiple stressors. Mandal et. al. (2012) found that, understanding the medium of instruction, was significantly related to performance in medical students. ${ }^{2}$ There is much literature available on the effect of medium of school education and performance of the students in various professional courses unlike in medical profession in India. So, the present study is an attempt to assess whether mode of instruction during school education really affects professional performance and whether students from English-medium schools perform better in MBBS academics than those from vernacular medium schools.

\section{Materials and Methods}

The present study is a multicentric retrospective observational study. The number of participants involved was 274 out of 350 students of both genders, passed in MBBS from four government medical colleges in Marathwada 
region of Maharashtra. The colleges included were Government Medical College, Aurangabad, SRTR Medical College, Ambajogai, Government Medical College, Latur and Dr. Shankarrao Chavan Government Medical College, Nanded.

Ethical approval was obtained from the Institutional Ethical Committee of Government Medical College, Aurangabad. Before enrolment in the study, informed written consent was obtained from all the students who were willing to take part in the survey. Permission of the Deans of all the institutions was sought. Students with diagnosed psychological disorder were excluded from the study. Basic data like age and sex was collected. The medium of instruction during their school education was recorded from their $10^{\text {th }}$ standard mark-sheets. Quantitative assessment of professional performance was done using their final MBBS marks, obtained in both practical and theory. The marks of final year MBBS were recorded from the mark-sheets available with the students or their academic record available in the academic section of the colleges involved in this study. Comparison of marks obtained in final MBBS was done among students from different media of instruction during their school education using one-way ANOVA in statistical software GrapPad Prism (Version 6.01).

\section{Result}

The study included 274 (78.29\%) students out of 350 students passed in the final year MBBS. Remaining students were unwilling to participate in the study. Out of total 274 participants, 158 were males and 116 were females. The median age of the participants was 19.42 years. Frequency distribution of students as per the medium of instruction of their school education before getting admitted to MBBS course is shown in table-1. Maximum number of participants $(67.15 \%)$ have got their school education in native Marathi language followed by English (25.55\%).

Table1: Distribution of subjects according to the medium of instruction during school education

\begin{tabular}{|l|c|}
\hline Medium of Instruction & Frequency (\%) \\
\hline Marathi & $184(67.15 \%)$ \\
\hline English & $70(25.55 \%)$ \\
\hline Urdu & $12(4.38 \%)$ \\
\hline Hindi & $8(2.91 \%)$ \\
\hline
\end{tabular}

In the current study, we found that students who learned in Hindi during their school education had achieved maximum mean percentage score $(60.90 \%)$ while Urdu medium students got the least marks $(57.66 \%)$ as indicated in Fig.1.

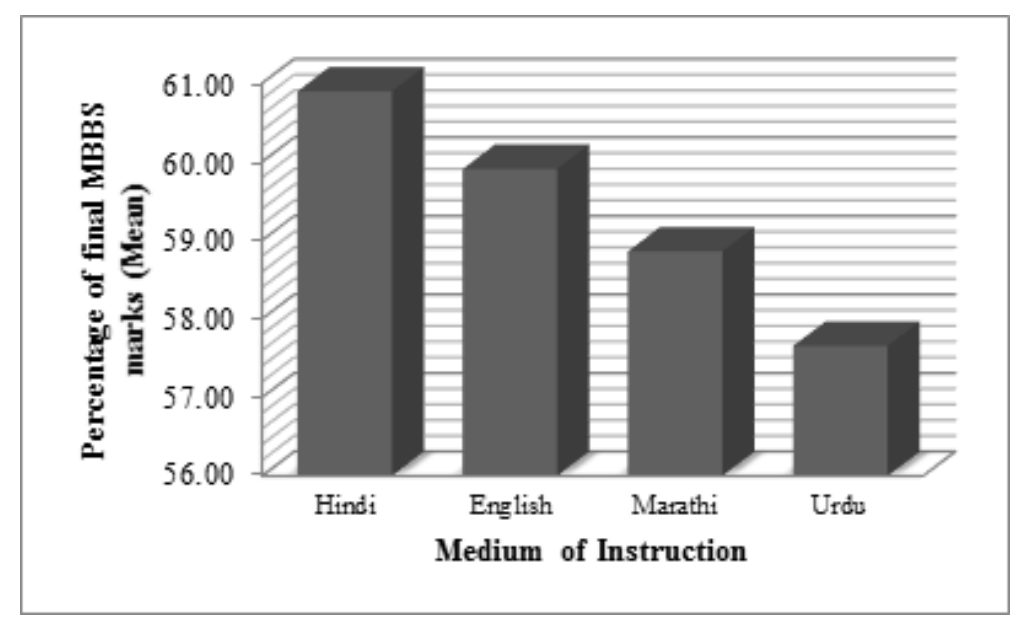

Fig. 1: Academic performance of medical students with different media of instruction during their school education

As shown in the table 2, when we compared the final MBBS marks of all the students belonging to different media of instruction during their school education, we did not find any statistically significant difference between their scores $(\mathrm{P}=0.1149)$. 
Table 2: Comparison of academic performance of medical students with different media of instruction during their school education

\begin{tabular}{|l|c|c|c|c|c|}
\hline $\begin{array}{l}\text { Medium of } \\
\text { instruction }\end{array}$ & Hindi & English & Marathi & Urdu & $\begin{array}{c}\text { P-value } \\
\text { (One-way } \\
\text { ANOVA) }\end{array}$ \\
\hline $\begin{array}{l}\text { Percentage of final } \\
\begin{array}{l}\text { MBBS marks } \\
\text { [Mean (SD)] }\end{array}\end{array}$ & 60.90 & 59.91 & 58.86 & 57.66 & 0.1149 \\
(NS) \\
\hline
\end{tabular}

$\mathrm{P}=$ NS: Statistically not significant.

\section{Discussion}

English is considered a foreign language for Indian students. All the professional institutions have English as a medium of education. There is a common belief in the society that students weak in English language may not understand and reproduce the knowledge in examinations and also, the failure and poor performance in examinations by the medical students may be because of this factor. So, in recent years there has been a dramatic surge in English medium schools in India with many parents insisting to admit their children in those schools rather than in vernacular schools. This hypothesis was assumed in our study. We included the freshly passed final year MBBS students and compiled their academic performance in university examinations. The present study shows statistically no significant difference between mean marks obtained by the students of different media of instruction in their school education. But, when compared individually, all the students that scored highest marks in the exam belonged to Marathi medium which is the most prevalent language in this region. This indicates that students from vernacular medium had no deficits in English language to the extent that can adversely affect their comprehension and performance. This disproves the general assumption that, to be proficient in medical academics, one needs command over English language.

Mother tongue is defined by UNESCO as "the language which a person acquires in early years and which normally becomes their natural instrument of thought and communication." According to UNESCO, mother tongue education is "Education which uses its medium of instruction a person's mother tongue, that is, the language a person has acquired in early years and which normally has become his or her natural instrument of thought and communication." The importance of mother tongue in the cognitive, linguistic, personal and educational development of students cannot be ignored. ${ }^{3}$

There is no doubt that the basic knowledge of English language is must for achieving excellence in medical education worldwide. Despite international communication among clinicians and scientists occurring almost exclusively in English, communication with patient and colleagues within individual countries, teaching, and some scientific activities are still conducted in the local mother tongues. ${ }^{4}$ The vast knowledge of medical sciences cannot be memorized but can be retained by understanding and active learning. A learner can do this efficiently by communicating in his own language.

In countries like India, the foundations of reasoning and memory in basic subjects are mostly founded in the vernacular languages i.e. primary language (L1), with minimal exposure to English as a secondary language (L2). Even then, we found statistically no difference in their performance on comparing with that of English medium students. This indicates that basic education in mother tongue may reinforce the learning in secondary language. Even though medium of instruction is English in Russia, China, Japan, Mexico and other countries, their medical education system also give enough importance to native languages other than English and they have produced excellent human resources trained in medicine as well as biomedical research. Many Indian students learn their languages to undergo medical training in these countries. ${ }^{5}$

Studies on advantages of teaching medicine in English, assisted by using student's mother tongue, had been done before in other countries. ${ }^{6-}$ 8 This inclusion of the mother language in teaching medicine is seen as a way to free learners from the linguistic bias of thinking in one language and studying in another i.e. students with background of vernacular medium school read medicine in English and interpret in vernacular languages. ${ }^{9}$

Many studies in literature show the important role of mother tongue for second language acquisition. Primary language (L1) helps learners to arrange and rearrange the secondary language (L2) data for better understanding and interpretation. Thus, L2 acquisition is a developmental process, assisted by L1.

When learning a new language, we build brain networks to process and represent the acquired words and syntax and integrate these with existing language representations i.e. the brain is able to reuse characteristics of the mother 
tongue when the new language being taught is grammatically similar. Results of a study by Weber et al (2016) indicated an overlap in neural mechanisms for native and new language constructions with sufficient structural similarities. ${ }^{10}$ Studies have shown positive effects of mother tongue on comprehension itself. Price et al (1999) observed that comprehension of words in mother tongue activated more of the temporal lobe including temporal pole than did words in second language. ${ }^{11}$

Similar results were obtained in a study conducted by An E He (2012) in China, who pointed out the potential advantages of systematic use of mother tongue as learning or teaching resource in target language instruction. They observed that use of L1 as learning and teaching resources provided a support for learners. By making explicit reference to learners' conceptual understanding of mother tongue, and by raising their conscious awareness of similarities and differences between Chinese and English, learners' existing comprehension could be enhanced. Also, using L1 as learning and teaching resources increases learning efficiency and smoothened the learning process. Taking advantage of what students have already known conceptually, strategically, and linguistically allowed a "all round development" and "intellectual continuity" in language development. ${ }^{12}$ Similarly, Sabbour et al (2012) suggested that teaching in Arabic language was appropriate in some specialties of medicine in Arab countires. ${ }^{9}$ Khattak et al (2005), in a similar study in Pakistan, concluded that there is no effect of language as a medium of education during primary and secondary school upon the results of university professional MBBS examinations. ${ }^{13}$

As we consider this as a pilot study, further research involving more number of students from different regions in India is suggested to get more details on this issue. Also, similar studies should be carried out on medical students to correlate media of instruction with their professional performance qualitatively by interviewing them and assessing through questionnaires.

\section{Conclusion}

The present study shows no significant effect of medium of instruction during school education on the performance of students in medical colleges. So, it gives a message to the community that it is needless to emphasize on English medium of instruction for school education and students from vernacular medium schools can very well cope with English language during medical academics. Learning medicine in English, being the universal medium of instruction, may prove more efficient if it is supported by teaching and learning major concepts in students' mother tongue.

\section{References}

1. Cheney GR, Ruzzy BB, Murlidharan K. A profile of the Indian education system. National Centre on Education and Economy, 2006.

2. Mandal A, Ghosh A, Sengupta G, Bera T, Das $\mathrm{N}$, and Mukherjee S, Factors Affecting the Performance of Undergraduate Medical Students: A Perspective; Indian J Community Med. 2012 Apr-Jun;37(2):126-9.

3. Kobia JM, The Challenge of Mother Tongue Education in Kenya, LWATI: A Journal of Contemporary Research. 2007: Vol. 4:101-19.

4. Baethge C. The Languages of Medicine. Dtsch Arztebl Int. 2008 Jan;105(3):37-40.

5. Anand A, Bammidi S, Medical education and training: implications for India. Ann. Neurosci. 2013 Oct; 20(4):133.

6. Drouin J. Educating future physicians for a minority population: a French-language stream at the University of Ottawa. Academic Medicine, 2002, 77(3):217-21.

7. Haidinger G, Frischenschlager O, Mitterauer L. Reliability of predictors of study success in medicine. Wiener Medizinische Wochenschrift. 2006, 156(13-14):416-20.

8. Al-Kateb B, Review of the history of the teaching of medicine in Arabic. Eastern Mediterranean Health Journal, 1999, 5(3):597-603.

9. Sabbour S.M., Dewedar S.A., Kandil S.K. Language barriers in medical education and attitudes towards Arabization of medicine: student and staff perspectives. EMHJ, 2012b, 16(12):1263-71.

10. Weber K, Christiansen MH, Petersson KM, Indefrey P, and Hagoort P. fMRI Syntactic and Lexical Repetition Effects Reveal the Initial Stages of Learning a New Language. The Journal of Neuroscience, 2016, 36(26):6872- 80.

11. Price C J, Green D W, Von Studnitz R. A functional imaging study of translation and language switching. Brain; 1999;122;2221-35.

12. An E He, Systematic use of mother tongue as learning/ teaching resources in target language instruction. Multilingual Education 2012, 2:1.

13. Khattak AM, Wazir F, Khan H, Ali S and Shah SH; Effect of Medium of Education During School on Performance of Students in Medical College. Gomal Journal of Medical Sciences. July-December, 2005, Vol. 3, No. 2;44-7. 